\title{
RESISTENCIA Y CANONIZACIÓN EN EL MICRORRELATO: DE LA TEORÍA Y CRIITICA A LAS ANTOLOGÍAS ESPECIALIZADAS
}

Xaquín NúÑez Sabarís

Universidade do Minho

\begin{abstract}
Trance gozoso, este de andar buscándole, imaginándole, un nombre a la criatura: microrrelato, minificción, ¿por qué no nanocuento?

Mientras le encontramos un nombre, con esta sensación incomparable de ir descubriendo la realidad de un nuevo continente, ojalá su pequeño fulgor, desde brevísimos textos literarios palpitantes de ficción verdadera, ilumine intensas fascinaciones narrativas. (Merino 2007: 13)
\end{abstract}

Esta cita que abre la minificción completa de José María Merino pone de relieve -tanto por la publicación en sí, como por las preocupaciones terminológicas- la irrupción de esta modalidad narrativa en el campo literario y su generalización a partir de los últimos años del xx. Los libros -antologías, colecciones, recopilaciones-, las revistas especializadas, los estudios monográficos y los artículos teóricos evidencian un creciente interés de público, crítica y teoría por las narraciones mínimas.

De ello nos ocuparemos en las siguientes páginas, en las que se pretende efectuar una aproximación a las definiciones y delimitaciones de esta modalidad narrativa, fundamentalmente a través de la producción teórica y crítica sobre el microrrelato y las antologías publicadas en España en la última década. No sin antes intentar situar el fenómeno en su contexto socio-cultural y literario, a partir de las transformaciones que la narrativa manifiesta a lo largo del pasado siglo. Por ello, en primer lugar, se efectuarán algunas analogías entre el microrrelato y ciertos aspectos que determinaron la evolución de la narrativa en general y la breve, en particular, durante el pasado siglo. Si "brevedad" y "narratividad" son los conceptos que definen el microrrelato con relación a otras formas (por ejemplo, Ródenas de Moya 2010: 185 o Andres-Suárez 2010: 49), en los siguientes capítulos realizaremos un repaso por algunas de las transformaciones habidas en la narrativa, por considerar que son un itinerario necesario hacia la estética de lo breve y sin el cual no se explica el auge que la minificción adquiere en la primera década del presente milenio. 


\section{LA BREVEDAD. LOS CAMINOS ABIERTOS POR EL CUENTO MODERNISTA}

Sin entrar a valorar todavía si el microrrelato constituye una variante del cuento o una modalidad genérica diferente, lo cierto es que el interés por las formas breves se remonta a los comienzos del siglo xx. De hecho, son varios los investigadores que sitúan su origen en las estéticas surgidas a partir del modernismo. Andres-Suárez, entre otros, advierte los antecedentes del microrrelato en una primera etapa localizada en el período modernista y vanguardista:

La primera de ellas, la de los iniciadores, recubre aproximadamente las décadas 1910-1940 y está marcada por las corrientes estéticas del Modernismo y las Vanguardias históricas. La primera, como ya se dijo, se inscribe en una tendencia general orientada hacia la depuración formal, conceptual y simbólica, que afectó a todas las artes y fue vehiculada por Rubén Darío, cuyo libro Azul (1888) tuvo un impacto determinante entre los escritores que cultivaron el microrrelato. (Andres-Suárez 2010: 35)

Pero, además, el contexto socio-cultural que explica la irrupción del microrrelato a inicios del xxı se asemeja en gran medida a las transformaciones de inicios del xx y la consolidación del cuento. Lagmanovich observa un idéntico Zeitgeist-espíritu de la época- entre ambos finales de siglo:

Ello ocurre de forma muy notoria en el tránsito entre los siglos $\mathrm{xIx}$ y xx, y se continúa en las primeras décadas de este último. Puede decirse que, después del simbolismo en literatura, después del neorromanticismo en música, después del predominio de tendencias de raíz romántica y realista en las artes plásticas, existe -sobre todo en Europa- un afán muy grande por diferenciarse de las tendencias decimonónicas y entrar decididamente en la modernidad. [...] En todas las artes en suma, hay una triple reacción: contra la ornamentación por sí misma, contra la excesiva extensión y contra la redundancia.

Nos encontramos ya en pleno siglo $x x$, y la consigna de las artes en este siglo puede condensarse en la fórmula que encontró la nueva arquitectura: "menos es más". (Lagmanovich 2005: 13)

Por lo tanto, a pesar de que los escritores del XIX, Pardo Bazán, Clarín o Palacio Valdés, cultivaron el cuento con notable éxito, la expansión editorial de la narrativa breve se produce a inicios del $x x$, consolidando la tendencia que se había iniciado en las últimas décadas del XIX a propósito del cuento ${ }^{1}$. La interrelación entre el incremento de posibilidades de publicación, merced a la fortaleza del mercado editorial y al auge de la prensa, y el cambio de paradigma estético motivado por el modernismo, explica el fenómeno literario de la narrativa breve en el principio de siglo. Por eso no es de extrañar, tanto por el paralelismo entre ambos contextos como por la proximidad formal, que muchas de las antologías

\footnotetext{
${ }^{1}$ De ahí que Merino (1998) haya aprovechado las celebraciones del 98 para conmemorar cien años del cuento español, dado el simbolismo histórico de la fecha y el respaldo a las formas breves en este periodo.
} 
de cuento o microrrelato actuales remonten su selección a los textos breves de Valle-Inclán, Azorín o Rubén Darío.

La abundancia con que se desarrolla la narrativa breve a inicios de siglo no se puede disociar de la modernidad literaria, ya que, en el Fin de Siglo, el cultivo de los géneros narrativos cortos constituye un auténtico fenómeno editorial ${ }^{2}$. La preferencia por la forma breve de los escritores modernistas tiene mucho que ver con el hastío de la novela extensa practicada por los realistas y naturalistas (Grass y Risley 1979: 19); es, por esta razón, que la mejor prosa de la época "no se halla en la novela sino en el cuento, poema en prosa o ensayo" (Phillips 1974: 261).

Por lo tanto, para los escritores de este periodo, la preferencia por esta modalidad genérica viene en gran medida motivada por la distancia que marcaba con las formas novelísticas decimonónicas, aunque no se debe exclusivamente a una nueva orientación estética, sino que en el desarrollo de las nuevas formas desempeñó un notable papel la expansión que la prensa adquiere a lo largo de este siglo, modificando significativamente los hábitos de lectura:

Por encima de los libros, que ya hemos visto escasos y minoritarios, el lugar físico donde la nueva literatura va a intentar la captura de su público es el periódico, como beneficiaria $-y$, a la vez, como consecuencia- de la gran expansión alcanzada por la prensa española durante la Restauración. (Mainer 1987: 60)

La estrecha vinculación entre la expansión de la narrativa breve y el auge de la prensa plantea la duda acerca de la circunstancia que más condicionó la eclosión de las formas breves: la pretensión de distanciarse de la novela realista o el acomodo a los márgenes espaciales que los periódicos ofrecían:

El estudio de estas colecciones de relatos breves plantea un doble problema: uno literario, ya que la boga de estas parece llegar en un momento de crisis del relato naturalista cuando el predominio de la introspección psicológica y el reemplazo del argumento complicado por la anécdota reveladora aconsejaban al escritor la reducción e intensificación del relato; otro crematístico, ya que cabría plantearse en qué medida la demanda industrial de novelas breves condicionó la oferta de los escritores. (Mainer 1987: 71)

Para Ezama Gil, el relato breve refuerza, sin duda, su identidad gracias a la difusión que consigue en la prensa periódica:

El relato breve afirma su identidad genérica y asegura su difusión en los años finales del XIX, gracias al apoyo que le dispensa la prensa periódica. La divulgación de que es objeto el género se ve favorecida por las dimensiones del mismo, que lo hacen asequible a cualquier tipo de publicación.

En la época que nos ocupa se hace patente una acusada tendencia hacia la brevedad, señalada por algunos escritores, y manifiesta en los marbetes de buen número de relatos: "novelas relámpagos", "cuentos pequeñitos", "microscópicas", "cuentos de un minuto", "pequeñas historias", "efímeras", "instantá-

${ }^{2}$ Vid. Ezama Gil (1998: 18). 
neas", "cuentos breves", "relatos breves" o "narraciones al vuelo" son algunos de ellos. En la consolidación de esta tendencia desempeña un importante papel el cronista Fernanflor, decidido partidario de las formas breves³. (Ezama Gil 1992: 26)

El auge de los nuevos mecanismos editoriales proporciona fuentes alternativas de ingresos a los autores de la segunda mitad del XIX $x^{4}$. Tanto los que surgen a partir de este periodo (en especial, Clarín y Pardo Bazán) como los que se inician literariamente en el Fin de Siglo, en modo alguno ajenos a las tentaciones de periódicos y revistas, cultivan, casi sin excepción, la narrativa breve: cuento y novelas cortas $^{5}$. El proceso era idéntico en casi todos ellos: a la publicación de los relatos en la prensa le seguía la recopilación en diferentes colecciones.

Este recorrido resulta semejante al que sigue en la actualidad el texto hiperbreve. Además, hoy, como ayer, se produce un movimiento de dispersión editorial, análogo al descrito, y que estimula la irrupción de determinadas formas literarias, que hasta hace unos años no habrían tenido cabida alguna en el mundo editorial:

En la última década, sin embargo, el mundo editorial español ha cambiado sus-

${ }^{3}$ La propia investigadora afirma, sin embargo, que no todos los escritores manifestaron la misma predisposición; algunos como Clarín o Ernesto Laguardia se opusieron. En el caso de este último de forma sarcástica, a la efervescencia de estos géneros breves.

${ }^{4}$ Mainer (1987: 71) aporta una cita de Fernández Flórez, crítica con la mercantilización del género: "El mismo autor no vacila en confesar su preferencia por el género, pero a la vez no puede evitar una irritada reacción contra la mercantilización de los cuentos (el género idóneo para periódicos, revistas gráficas, almanaques) y los relatos breves, rasgo que era todo un fenómeno social en 1918, cuando Fernández Flórez prologaba la colección de estos últimos titulada Silencio: «En España hay muy pocos cuentistas y muchísimas personas que escriben cuentos. Casi todos estos cuentos tienen más relación con el aparato digestivo que con el cerebro o con el corazón. Procuraré explicar la génesis. El literato, o aspirante a tal, yace derrumbado en el diván de un café. Los movimientos peristálticos de su estómago sobresaltan en el secreto interior de la víscera media tostada mal mordida. Cuando esto ocurre y algún vecino de mesa ha pedido un roast-beef, la melancolía y el afán inmoderado de riquezas hallan abierto el camino del alma. Entonces el hombre derrumbado suele pensar que le faltan cinco duros. Decir cinco duros es suscitar en él la idea de escribir un cuento [...]. Lo que digo de él puede igualmente ser aplicado a la novela breve, salvando apenas un ligero matiz: detrás del cuento están veinte bistecs con patatas; detrás de la novela corta está un gabán o una mesada de la casa de huéspedes»".

Si nos situamos en el contexto actual y la temática que nos ocupa, Valls (2008: 10) previene contra la excesiva facilidad de publicación del microrrelato: "Otra cosa, dada su extrema brevedad, es lo fácil que pueda resultar componer un microrrelato, y la cantidad de piezas que se publican, en diarios, revistas o en la red, sin una mínima entidad literaria; aunque me atrevería a afirmar que no muchas más que poemas o novelas mediocres".

${ }^{5}$ A menudo eran colaboraciones en prensa realizadas por encargo, para efemérides concretas Piénsese en los cuentos de Valle-Inclán "Nochebuena" o "La adoración de los Reyes", recogidos posteriormente en la colección Jardín umbrío. También algunas colecciones de microrrelatos obedecen a una lógica idéntica: "Borges nos previno contra la charlatanería de lo breve, pero no pudo advertirnos contra aquellos otros textos llamados hoy ultracortos o hiperbreves (se componen apenas de una o dos líneas). Aunque no siempre sean ocurrencias, claro está, tienden -más a menudo de lo que sería deseable- a ser simples alardes de ingenio. Y eso que el escritor argentino no tuvo que sufrir ni los denominados microrrelatos de Verano, ni los de Navidad, literatura de encargo en auge, parece ser que solo en España, mercenaria donde las haya, con frecuencia solo cultivada -se nota que con una cierta desgana-, por aquellos autores menos familiarizados con el género (Valls 2008: 26). 
tancialmente. Puede decirse que la evolución que sufrió en los años ochenta -y que perfeccionó en los noventa- llevó al mercado a una situación inviable y de forma natural ha vuelto al sistema natural del siglo pasado. La perspectiva estrictamente empresarial de los grandes grupos editoriales provocó la compra y explotación de sellos editoriales independientes. En pocos años, menos de diez editoriales copaban más del $90 \%$ del mercado y se adentraban en otros medios de comunicación pública (Planeta, Prisa, Anaya...). Esta sobredimensión empresarial demostró ser un territorio excelente para el cultivo de los pequeños huecos que dejaban las editoriales gigantes. Con el cambio de siglo comenzaron a aparecer editoriales independientes, muy especializadas, para lograr así un nicho de mercado suficiente. La consecuencia fue un gran aumento de la "bibliodiversidad" y un enriquecimiento de catálogos hasta ahora desconocido. (González Ariza 2012: 92)

En consecuencia, las posibilidades editoriales facilitan también la acogida de las formas breves que recorren un itinerario similar al seguido por el relato breve modernista, ya que muchos microrrelatos pasan de la publicación en revistas, prensa, blogs o incluso twitters a la reunión en antología o colecciones ${ }^{6}$. De hecho, la profusión terminológica mencionada por Ezama no resulta muy diferente de la actual amplitud de designaciones (minicuento, minificción, nanocuento...) que acompaña a los textos hiperbreves. Cabe todavía establecer alguna analogía más, si se tiene en cuenta el carácter reivindicativo del que hacían y hacen gala los autores de cuentos y microrrelatos. El atrevimiento resulta a menudo un arma arrojadiza frente a los formatos literarios más convencionales:

He aquí un libro de juventud, un libro escrito en esa edad dichosa de sueños y de esperanzas. ¡Hoy esa edad se me aparece ya casi lejana! Al releer estas páginas, que después de tantos años tenía casi olvidadas, he sentido en ellas no sé qué alegre palpitar de vida, qué abrileña lozanía, qué gracioso borboteo de imágenes desusadas, ingenuas, atrevidas, detonantes. Yo confieso mi amor de otro tiempo por esta literatura: la amé tanto como aborrecí, esa otra, timorata y prudente, de algunos antiguos jóvenes, que nunca supieron ayuntar dos palabras por primera vez, y de quienes su ruta fue siempre la eterna ruta, trillada por todos los carneros de Panurgo. (Valle-Inclán 1908: 13).

Así se expresaba Valle-Inclán a propósito de la reedición de sus novelas cortas y así se expresaron recientemente, a título de manifiesto, diversos autores en la antología de cuentos Pequeñas resistencias. Tanto el título de la compilación, como el epígrafe del vindicativo texto "La rebeldía breve" no dejan lugar a dudas de sus propósitos:

Las novelas -aunque no todas- venden más; los cuentos -aunque con excepciones- venden menos. ¿Son acaso por eso mejores las novelas? ¿Es justo seguir presentando como argumento literario lo que es una simple jerarquía comer-

\footnotetext{
${ }^{6}$ González Ariza (2012: 94) vincula la generalización del género con los hábitos asociados a la era digital, hasta el punto que subraya la importancia de los ciento cuarenta caracteres del Twitter en la preferencia de lo hiperbreve sobre lo breve.
} 
cial? Muchos de los abajo firmantes no solo no nos oponemos a las novelas, sino que además las hemos escrito y publicado. Y a pesar de eso, o quizá por eso mismo, quisiéramos expresar nuestra perplejidad ante ese arraigado fenómeno que podría denominarse la oficialización de la -supuesta-inferioridad del cuento. Una cosa es que todos estemos más o menos sujetos a las leyes del mercado, y otra bien distinta es confundir el valor con las ventas, los méritos con los numeritos, el cuento con el cuánto. (Neuman 2010a: 7)

En suma, al efectuar un paralelismo entre lo ocurrido en ambos inicios de siglo, no se pretende relacionar de modo genealógico un momento como el punto de partida del otro (parentesco que a menudo se subraya como elemento legitimador del microrrelato como género), sino poner de manifiesto el camino convergente de la estética modernista hacia al actual interés por las formas mínimas. Ródenas de Moya (2010: 194) vincula "el cultivo de la máxima depuración y concentración elocutivas" en el texto narrativo con "la metamorfosis que experimentan las formas artísticas a partir del simbolismo en todo Occidente". Para este escritor (Ródenas de Moya 2010: 196), en continuidad con lo ya dicho en este apartado, la estética de la brevedad ahonda sus raíces en el "pensamiento fragmentado", opuesto a la racionalidad ilustrada del XIX.

De modo que la brevedad tratada en este epígrafe nos lleva a otro aspecto muy vinculado a la evolución de la narrativa a lo largo de todo el siglo anterior: la fragmentación.

\section{LA FRAGMENTACIÓN DE LA NARRATIVA: HACIA LA POSMODERNIDAD}

Si el cuento ensanchó las modalidades genéricas durante el xx, la aparición del cine y la evolución de la narrativa -no solo la corta- modificaron también los hábitos de lectura y, por lo tanto, la pragmática del microrrelato puede relacionarse también con las transformaciones habidas en la narrativa posmoderna en general. Como afirma Noguerol (2010: 78), el "establecimiento del 'canon' del micro-relato es paralelo, por consiguiente, a la formalización de la estética posmoderna".

Para Andres-Suárez (2010: 36), "el hallazgo estético del microrrelato en España se debe esencialmente a dos fenómenos y a dos figuras clave. Por una parte, al proceso de depuración formal que sufrió la poesía de la mano de Juan Ramón Jiménez y, por otra, a la fragmentación de la novela".

Villanueva (1977) advierte que la fragmentación es uno de los rasgos definidores de la novela durante el $\mathrm{xx}$, cuyos derroteros permiten cuestionarse si se trata de una continuación, transformación o ruptura del camino transitado por esta modalidad genérica desde sus orígenes renacentistas hasta la madurez decimonónica. Cuestión, lo veremos más adelante, que inspira también algunos de los debates habidos acerca da la autonomía del microrrelato y el cuento.

La progresiva desintegración de la narrativa confluye en el cultivo de las formas hiperbreves, de ahí que alguna de las formulaciones utilizadas para este tipo de micronarrativas se vinculen con la terminología del mundo de la ciencia, como se expresa en las designaciones "nanocuento" o "literatura cuántica" 
(Andres-Suárez 2010: 12) y que expresan la opción por lo mínimo que en la actualidad alcanza los diferentes ámbitos de lo científico, lo social o cultural:

Para llegar a la poética de la sustracción, al menos es más, de Mies van der Rohe, se ha recorrido un largo trecho, desde la miniatura pictórica a la microfotografía (www.sciencieart.nl), la nanotecnología y la minicomputación; sin olvidar el llamado microperiodismo (Vicente Verdú dixit); la ya cotidiana minifalda o el coche Nano, vehículo de bajo coste creado por una empresa de la India. Pero ahora parece que un nuevo viento cultural azota el paisaje con el regreso de nuevas fuerzas de lo nano (lo supernano), lo micro... Así, tras la aparición de los microblogging de Twitter (mensajes que tienen como límite ciento cuarenta caracteres, en los que se cuenta lo que uno está haciendo en ese momento), acaban de nacer los llamados movilcineastas, los autores de cine por móvil, quienes disponen de un minuto para contar una historia, e incluso ya tienen su propio certamen, el Movil Film Fest (junio de 2007). (Valls 2008: 299)

De forma paralela, también la novela del xx importó las novedades que el nuevo siglo traía en el terreno de la filosofía o las ciencias experimentales:

El xx disocia lo verdadero de lo absoluto, distinguiendo escepticismo de relativismo. A este relativismo contribuyen concretamente las aportaciones filosóficas, ideológicas y científicas más notables de nuestra época. El marxismo defiende que las instituciones y la moral de una sociedad no son inmanentes e inalterables, sino reflejo de su clase dominante; la fenomenología, disciplina estrictamente descriptiva opuesta a las cadenas de razonamientos que constituyen el espíritu cartesiano, se coloca antes de toda creencia y todo juicio y explora simplemente lo dado [...]. Por su parte, Albert Einstein, en 1905 y 1916, destruye los postulados de la mecánica clásica negando el valor absoluto del tiempo newtoniano. [...]

La realidad, parecía proclamar Einstein para el intelectual de entonces, depende del punto de vista de cada cual, y sus ideas, liberar al arte, la psicología, la sociología, etc. de la dictadura de las leyes mecanicistas. (Villanueva 1977: 46)

Rescato de Núñez Sabarís (2009: 18) un fragmento de la novela de Érico Veríssimo, Caminhos cruzados, de 1935, y que problematiza la cuestión epistemológica de la novela del xx, en relación a la recepción que la teoría de la relatividad einsteniana plantea:

A vida, prezado leitor, é uma sucessão de acontecimentos monótonos, repetidos, sem imprevisto. Por isso alguns homens de imaginação foram obrigados a inventar o romance.

O Homem, na Terra, nasce, vive e morre sem que lhe aconteça nenhuma dessas aventuras pintorescas de que os livros estão cheios num romance. Quando saímos da leitura duma história de amor, ficamos surpreendidos ao nos encontrarmos na vida real diante de pessoas e coisas absolutamente diferentes das pessoas e coisas das fábulas librescas.

Repito: a vida é monótona. Queres um exemplo frisante, vívido, observado, verificado? Ei-lo, leitor amigo: moro numa rua suburbana cujo ponto culminante é a janela do meu quarto. E que vejo eu do meu posto de observador 
céptico? O mesmo ramerrão cotidiano, os mesmos quadros monótonos. Na casa fronteira há sempre uma senhora vestida de preto que fica sentada na sua cadeira de balanço enquanto a filha anda dum lado para outro, fazendo eu nem sei quê. Mais adiante vejo um homem que se senta numa preguiçosa para ler o jornal, cercado dos filhos que berram, enquanto o seu gramofone toca uma música aborrecível que se repete todos os dias. No quintal próximo um moleque ladino joga pedras no pombal da casa vizinha.

São cenas de todo o dia. Nenhum acontecimento romântico quebra a calma desta rua e de seus habitantes. Onde os dramas de que falam os romancistas? Onde as angustias que cantam os poetas?

Foi depois de muito observar e meditar que eu cheguei à conclusão de que um observador colocado num ângulo especial poderá ter uma visão diferente e nova do Mundo. (Veríssimo 2005: 299)

La reflexión del personaje, el profesor Clarimundo -un parodiado entusiasta de las teorías einstenianas-, refleja una de las preocupaciones de la novela contemporánea, en relación a su discontinuidad y la ruptura de un discurso -un punto de vista- hegemónico, que ya no es posible articular. En España, la novela que más se aproxima en este punto y que tanto marcará la narrativa en sus años sucesivos es La colmena (1951). También opta por una secuencia fragmentada, discontinua y desordenada que descompone la unidad narrativa en múltiples secuencias, cuyo resultado no se puede disociar del proceso que converge en las narrativas -y micronarrativas- contemporáneas. Véase, si no, el conocido episodio del hombre que se suicidó porque olía a cebolla:

Estaba enfermo y sin un real, pero se suicidó porque olía a cebolla.

- Huele a cebolla que apesta, huele un horror a cebolla.

-Cállate, hombre, yo no huelo nada, ¿ quieres que abra la ventana?

-No, me es igual. El olor no se iría, son la paredes las que huelen a cebolla, las manos me huelen a cebolla.

La mujer era la imagen de la paciencia.

- ¿Quieres lavarte las manos?

-No, no quiero, el corazón también me huele a cebolla.

-Tranquilízate.

-No puedo, huele a cebolla.

-Anda, procura dormir un poco.

-No podría, todo me huele a cebolla.

-¿Quieres un vaso de leche?

-No quiero un vaso de leche. Quisiera morirme, nada más que morirme, morirme muy deprisa, cada vez huele más a cebolla.

-No digas tonterías.

-¡Digo lo que me da la gana! ¡Huele a cebolla!

El hombre se echó a llorar.

- ¡H Huele a cebolla!

-Bueno, hombre, bueno, huele a cebolla.

- ¡Claro que huele a cebolla! ¡Una peste! La mujer abrió la ventana.

El hombre, con los ojos llenos de lágrimas, empezó a gritar.

- ¡Cierra la ventana! ¡No quiero que se vaya el olor a cebolla!

-Como quieras. La mujer cerró la ventana. 
-Quiero agua en una taza; en un vaso, no.

La mujer fue a la cocina, a prepararle una taza de agua a su marido.

La mujer estaba lavando la taza cuando se oyó un berrido infernal, como si a un hombre se le hubieran roto los dos pulmones de repente.

El golpe del cuerpo contra las losetas del patio, la mujer no lo oyó. En vez sintió un dolor en las sienes, un dolor frío y agudo como el de un pinchazo con una aguja muy larga.

-¡Ay!

El grito de la mujer salió por la ventana abierta; nadie le contestó, la cama estaba vacía. Algunos vecinos se asomaron a las ventanas del patio.

-¿Qué pasa?

La mujer no podía hablar. De haber podido hacerlo, hubiera dicho:

-Nada, que olía un poco a cebolla. (Cela 1989: 363)

La inconcreción del texto, su brevedad y su carácter autónomo en el conjunto de la obra permiten su identificación formal como microrrelato, incluso su temática y abstracción resultan próximas a aspectos recurrentes en el repertorio microrrelatístico. Tal es su proximidad que Díez (2007: 383) incorpora este texto a su antología de cuentos e historias mínimas ${ }^{7}$.

Si vinculamos el efecto estético producido por este fragmento -potenciador, por otro lado, de la dimensión social y existencialista que se pretende en $L a$ colmena-con el carácter discontinuo que el discurso quebrado de la narrativa del xx propone, nos encontramos con una apuesta por una estética de la elipsis, en la cual los espacios de indeterminación y la cooperación del lector resulta indispensable para completar el significado textual (Noguerol 2010: 94). El fragmento final del capítulo vi, con su inconcreción lírica, apunta a una línea muy explorada en la narrativa mínima:

La señorita Elvira se despierta pronto, pero no madruga. A la señorita Elvira le gusta estarse en la cama, muy tapada, pensando en sus cosas, o leyendo Los misterios de París, sacando solo un poco la mano para sujetar el grueso, el mugriento, el desportillado volumen.

La mañana sube, poco a poco, trepando como un gusano por los corazones de los hombres y de las mujeres de la ciudad; golpeando, casi con mimo, sobre los mirares recién despiertos, esos mirares que jamás descubren horizontes nuevos, paisajes nuevos, nuevas decoraciones.

La mañana, esa mañana eternamente repetida, juega un poco, sin embargo, a cambiar la faz de la ciudad, ese sepulcro, esa cucaña, esa colmena...

¡Que Dios nos coja confesados! (Cela 1989: 397)

\footnotetext{
${ }^{7}$ Roas (2010: 23) afirma que la práctica de recortar fragmentos de textos mayores y leerlos como microrrelatos es una práctica editorial frecuente. Considera, sin embargo, que obedece a la confusión de la brevedad con lo fragmentario (en el sentido de incompleto), cuando esta es una consecuencia de aquella y no un elemento constitutivo. Valls (2008: 21) se desmarca asimismo de esta práctica: "A nuestros efectos, carece de sentido, por tanto, rastrear la narrativa existente en busca de frases que puedan leerse a modo de posibles microrrelatos intercalados en otros textos de mayores dimensiones". Merino (2010: 234), a su vez, concluye que "el arrancar fragmentos a textos completos, que nos permitiría extraer cientos de microrrelatos y frases chispeantes de las obras de Shakespeare o de Cervantes, de las metáforas de Lorca o Neruda, no dejaría de ser una manera poco literaria de hacer picadillo la literatura".
} 
Andres-Suárez (2010: 51) indica que la elipsis es una necesidad estructural de todo microrrelato $y$, en consecuencia, la novela de mediados del xx origina un horizonte de expectativas que exigen un lector implícito muy diferente al de la narrativa decimonónica ${ }^{8}$. A partir de la estética posmoderna, se explica que tanto la narrativa larga como la breve potencien estos aspectos, lo cual exige unos hábitos de lectura más avezados y muy perceptibles en el microrrelato:

Los libros, al igual que ocurre en los volúmenes de cuentos y de poesía, se generan por yuxtaposición o coordinación. Pero lo que resulta evidente es que necesitan de un lector activo, exigente, habitual, que esté familiarizado con la historia cultural y literaria. Podría decirse, por tanto, como una generalización, que la lectura de un buen libro de microrrelatos precisa un esfuerzo y una preparación mayores que la que acostumbramos a poner en juego al encarar buena parte de las novelas que se publican hoy. (Valls 2008: 13)

Roas (2012: 60) sin negar la complicidad lectora que la concentración narrativa exige, discrepa que estemos ante una forma cualitativamente diferente de descodificar el texto narrativo:

... la reivindicación de la exigente actividad descodificadora del lector de microrrelatos en absoluto puede ser proyectada como esencia únicamente destilada por esa forma narrativa, sino que responde a cualquier proceso de actualización activa del texto por parte del lector (tal como, ya indiqué, reclamaron Eco o Iser) puesto que todo discurso narrativo -tenga la extensión que tengareclama un lector cocreador.

La cuestión de la recepción, en todo caso, pone de relieve que, a la hora de discutir los límites definidores del microrrelato, deberá atenderse a un análisis de la producción y recepción textuales y no únicamente a la descripción morfológica y estructural (Roas 2010: 12). Por ello, no puede dejar de señalarse el proceso de intensidad y depuración narrativa que acomete la novela a lo largo del xx y el horizonte de expectativas que aportan el cine y la cultura audiovisual, allanando, de este modo, el terreno para una experiencia lectora que acoge sin grandes traumas en los albores del presente siglo la cristalización narrativa de las formas breves.

\section{EL MICRORRELATO: UNA POÉTICA DE LA LEGITIMACIÓN}

Al inicio del presente trabajo se ha advertido del intenso debate crítico que el microrrelato ha suscitado y todavía suscita. Las monografías (Valls 2008 o Andres-Suárez 2010), antología de artículos (Roas 2010), los congresos específicos celebrados o las revistas especializadas (El cuento en red) dan buena muestra de ello. Esta actividad científica viene sin duda motivada por el afán de definir una modalidad narrativa que ha irrumpido con especial fuerza en los últimos años. Estas aproximaciones críticas, amén de ofrecer una disección rigurosa de las parti-

\footnotetext{
${ }^{8}$ Merino (2008: 210-211) también alude a la necesaria cooperación del lector en las partes decimoquinta y decimosexta de su "microtratado teórico", "La glorieta de los fugitivos".
} 
cularidades que entraña la minificción, pretenden de forma más o menos explícita legitimar y reforzar la autoridad literaria del microrrelato. No en vano, Valls (2008: 305) detalla la poca permeabilidad que el campo literario y cultural ofrece hacia esta forma:

Lo curioso del caso es que todavía hoy hay autores que, aunque lo cultivan con fortuna, se resisten a aceptarlo, o bien no tienen conciencia de que sus textos se comprenden mejor formando parte de esa nueva modalidad narrativa. Tampoco la mayor parte de los editores parecen tener noticia, a ciencia cierta, de tales peculiaridades genéricas. Y si no hace tanto tiempo arrugaban la nariz cada vez que un autor les llevaba un libro de cuentos, no es difícil imaginarse la cara que deben de poner hoy cuando se presentan con un volumen de microrrelatos bajo el brazo, una dimensión narrativa aún menos domesticada si cabe. Mientras que los periodistas culturales (suelen ser los últimos en enterarse de todo, a la vez que se prestan a apoyar lo obvio, lo insustancial y extravagante), no saben qué hacer -y aquí podríamos añadir también a los críticos- cuando les cae en las manos uno de dichos volúmenes. (Valls 2008: 305)

Páginas atrás nos hemos referido al manifiesto reivindicativo que se lanza en las páginas de la antología Pequeñas resistencias (Neuman 2010a), aunque en este caso tenga por objeto la narrativa breve en general (cuento y microrrelato). Con idénticos propósitos a los trazados en la reivindicación preliminar, el antólogo acompaña la selección de textos con una poética personal de cada uno de los autores. Esta opción de acompañar el acto creativo de una reflexión -seguida posteriormente por otras antologías- evidencia la pretensión de subvertir la condición periférica de la narrativa breve y dotarla de centralidad literaria?.

Con todo, creadores y teóricos del microrrelato juegan a menudo a postularse en el centro del campo, por un lado, y, por otro, a mantener su cuota de transgresión literaria. No en vano, Noguerol (2010: 86) observa el carácter ex-céntrico del microrrelato, como producto posmoderno que es. Así, varias de las definiciones y caracterizaciones del mismo huyen de todo sesgo académico optando por marcas paródicas como el decálogo, alguno de marcado acento irónico y transgresor. Por ejemplo el "nodecálogo" de Rodríguez (2011: 9)10.

1. Nunca renuncie a ser un Balzac, un Stendhal o un Proust, aunque de su pluma solo surja una línea al año.

2. De los maestros, copie lo que hacen y no haga lo que dicen.

3. No sucumba a la tentación de llevar un extenso cuaderno de notas o de sacar mucha punta a su lápiz.

4. Recuerde que su nada efímero propósito requiere, sin embargo, de lo efímero: el sentido de la historia, la muerte del individuo, el chiste de moda.

\footnotetext{
${ }^{9}$ A propósito del microrrelato, Lagmanovich (2008: 41) alude a la marginalidad canónica y académica del microrrelato.

${ }^{10}$ Armando Alamís (2011) y Neuman (2011) optan también por un texto de características similares al citado. De igual modo Valls (2008) describe las características del microrrelato también a través de un decálogo.
} 
5. Anote siempre al acecho de sus propios monstruos: dinosaurios, dioses, fantasmas, vampiros, reflejos en el espejo y entes similares; algunos como la madre, el hijo o el padre son espeluznantes.

6. No haga chillar a las pobres palabras, pero tampoco les permita salirse del huacal. Evite el desperdicio: que la situación se comprima en un puño y que lleve sus huellas digitales.

7. No olvide, nunca, al lector: su complicidad es imprescindible. Para mejores resultados, invéntese uno.

8. Redacte su relato: recorte, añada, hilvane, recorte nuevamente (esta cláusula, por ejemplo, podría ser recortada).

9. Si se atreve, ofrézcalo a la publicación, y espere pacientemente a que nadie lo tome en serio.

La mayoría de las intervenciones críticas y teóricas pretenden subvertir el statu quo de la micronarrativa y fijar su lugar en el sistema literario. Por ejemplo, a partir de la búsqueda de una denominación comúnmente aceptada para la nueva modalidad. Lagmanovich (2005: 11), Valls (2008: 18) o Andres-Suárez (2010: 25) refieren varias de las designaciones utilizadas. Todos optan, como Roas (2010), por el término microrrelato, hoy ampliamente asentado teórica y críticamente. Pese a ello, Lagmanovich (2005: 12) recuerda la amplia utilización de minificción y Andres-Suárez (2005: 27) que esta es la forma más utilizada en Hispanoamérica.

Además de la cuestión terminológica, un apartado constante en la mayoría de los trabajos teóricos aborda la tradición del microrrelato y efectúa un recorrido histórico que se remonta diacrónicamente a la publicación de textos hiperbreves de diversa índole, situando a menudo el punto de partida en los inicios del xx. Sin duda que esta reflexión está muy vinculada a la búsqueda de la legitimación aludida. Ya se ha dicho que gran parte de los trabajos citados opta por situar el inicio de las formas breves en el modernismo, a pesar de la constancia de haber existido siempre expresiones narrativas mínimas. Juan Ramón Jiménez, Borges, Kafka, Monterroso son varios de los nombres aludidos, cuya centralidad refuerza el prestigio defendido.

Bien es cierto que todos observan un cambio cualitativo del microrrelato contemporáneo -posmoderno- que se consolida en el sistema literario, con sus dispersos antecedentes. Por ello, hay una descripción de sus características encaminada a delimitarlo genéricamente y subrayar su autonomía. A pesar de referir el parentesco con otras formas literarias y su hibridismo, la mayoría de los posicionamientos teóricos optan por afirmar su identidad como género literario independiente del cuento. Valls (2008: 20) incluso arriesga una definición:

Quinto (y casi una definición). El microrrelato es un género narrativo breve que cuenta una historia (principio este irrenunciable) en la que impera la concisión, la elipsis, el dinamismo y la sugerencia (dado que no puede valerse de la continuidad), así como la extrema precisión del lenguaje, que suele estar al servicio de una trama paradójica y sorprendente. A menudo, se presta a la experimentación y se vale de la reescritura o lo intertextual; tampoco debería faltarle la ambigüedad, el ingenio ni el humor. 
El monográfico de Valls y los demás trabajos consultados amplían de alguna manera lo sintetizado en esta definición. Para Lagmanovich (2005) el microrrelato se define en función de dos parámetros: la brevedad y la ficcionalidad, y distingue cinco tipos: ejemplos de reescritura y parodia; discurso sustituido; escritura emblemática; discurso mimético y bestiario y fábula. Los ejes de brevedad y narratividad también son aducidos por Andres-Suárez (2010) como los elementos identificadores del microrrelato. Añade, esta última, además, tres estrategias para reducir el microrrelato a su mínima expresión: la intertextualidad temática y formal, lo fantástico y el humor.

Finalmente, Noguerol (2010) advierte -ya se ha dicho- una identificación entre los rasgos definidores del microrrelato y la estética posmoderna. Enumera seis características constituyentes: el escepticismo radical, el carácter ex-céntrico de los textos, el golpe al principio de autoridad, su carácter abierto, el virtuosismo intertextual y el recurso al humor y la ironía.

El esfuerzo descriptivo realizado en la mayoría de las aproximaciones teóricas citadas -Lagmanovich (2005), Valls (2008) o Andres-Suárez (2010)- concluye que estamos ante un género nuevo e independiente de cualquiera de las demás modalidades de narrativa breve: el cuento o novela corta. Sin embargo, este posicionamiento dista de ser unánime en la crítica dedicada al microrrelato, tal como observa Álamo Felices (2010: 211), sintetizando las dos posturas que concitan el debate genérico:

La cuestión es interesante debido a la inexistencia de acuerdo dentro de su esfera investigadora, pues mientras unos defienden el microrrelato y la minificción como un nuevo género narrativo, otros estudiosos vienen a encuadrarlo en tanto que variante exagerada de las técnicas cuentísticas.

De modo que si los rasgos anotados hasta el momento sirven para algunos críticos como base para apuntalar la autonomía genérica del microrrelatos, otros -si bien perciben una potenciación de los rasgos del cuento- en modo alguno perciben que estemos ante una modalidad genérica diferente, tal como refiere Valles Calatrava (2008: 54) en su teoría sistémica de la narrativa.

Esta línea argumental es compartida por Roas (2008 y 2010) y Ródenas de Moya (2008). El primero, a pesar de admitir la identidad literaria del microrrelato, discrepa que estemos ante un género diferente:

A estas alturas, negar el uso o la propia denominación "microrrelato" resulta algo absurdo. No es esa mi intención, pues ya se ha impuesto en el sistema literario actual para nombrar a una forma narrativa particular: escritores, críticos, antólogos, lectores, editores, nadie duda en utilizar este término para referirse a textos narrativos ficcionales muy breves. Aunque asumiendo que tal identificación viene determinada por "presiones paratextuales", por un acuerdo social, y no por rasgos textuales exclusivos de esta forma narrativa, como enseguida veremos. (Roas 2008: 47)

Ródenas de Moya (2008: 77) advierte, en la misma línea, que "no creo que haya buenas razones para diferenciar entre un cuento breve y otro brevísimo 
(¿cuál es el alcance del superlativo?)” y Roas (2010) define las características del microrrelato a partir de cuatro ejes: el discursivo, formal, temático y pragmático, pero señala de forma conclusiva que no estamos ante una forma independiente desde el punto de vista genérico, sino ante una subcategoría del cuento:

\begin{abstract}
Las múltiples investigaciones precedentes sobre el microrrelato han acotado de manera muy detallada los diversos rasgos recurrentes que intervienen en la construcción formal y semántica, pero ninguno de ellos (ni siquiera sus combinaciones) permiten, a mi entender, establecer un estatuto genérico autónomo para el microrrelato. La única diferencia que podría distinguirle del cuento es su hiperbrevedad, pero esta, como ya dije, más que una característica, es una consecuencia estructural de los rasgos y procedimientos formales empleados, que, insisto una vez más, son los mismos que aparecen en el cuento. En definitiva, nos hallamos ante una variante más de la continua reinvención que caracteriza el cuento común. (Roas 2010: 39)
\end{abstract}

Por último, Álamo Felices (2010: 218), quien se adhiere a la unidad narratológica del microrrelato y el cuento, desconfía del estatuto genérico de la hiperbrevedad -en detrimento de la matriz canonizada del cuento- como un síntoma de la descomposición ideológica y metadiscursiva de la posmodernidad:

La nueva situación ideológica contemporánea, derivada del neo-liberalismo dominante/globalizante/totalizador; que no es otra cosa que la transformación cualitativa del capitalismo triunfante a escala mundial, y que ha empapado de la denominada posmodernidad todos los discursos de la actual crítica cultural, política, económica e intelectual, ha derivado en una triple desconfianza: el, hasta ahora, consolidado estatuto de la realidad; las relaciones e implicaciones entre el lenguaje y la referida realidad, que estaban consolidadas en esa intalterabilidad; y, por último, la crisis de los metadiscursos.

En suma, el debate acerca de la identidad genérica del microrrelato está instalado en torno a la discusión científica sobre las formas hiperbreves. De todos modos, si tenemos en cuenta la escasa centralidad académica del microrrelato que menciona Lagmanovich ${ }^{11}$ y analizando la cuestión en clave sistémica, se observa una importante concentración, coincidencia y ambivalencia entre académicos, críticos y productores (antólogos, autores) del microrrelato y, en consecuencia, una comunidad cultural, científica y académica mucho menor que en otros géneros o formas literarias. La tendencia habitual a subrayar la identidad genérica contribuye, en estos casos, a reforzar un repertorio que, por inherencia, fortalece las posiciones de dichos agentes en el sistema literario $\mathrm{y}$, por consiguiente, no puede dejar de estar presente e influir en los debates consignados y en las consecuentes posturas adoptadas.

\footnotetext{
11 "A diferencia de los géneros más tradicionales, la minificción no ha caído aún bajo la supervisión tiránica de las academias, los ministerios de educación, los grandes periódicos y las editoriales importantes" (Lagmanovich 2008: 41).
} 
Con todo, y al margen de la cuestión planteada, dicho sistema tiende a subrayar cada vez más la autonomía del microrrelato, acentuando su espacio social y editorial y reforzando las opciones paratextuales que lo identifican terminológicamente (Roas 2008: 47). De modo que en la última década se comprueba cómo los diferentes agentes de dicho campo (escritores, lectores, mercado o académicos) refuerzan la identidad del microrrelato, como se puede extraer del análisis de las antologías dedicadas a esta modalidad ${ }^{12}$.

\section{LA CONSOLIDACIÓN DEL MICRORRELATO: LAS ANTOLOGÍAS}

El número de antologías publicadas en el espacio literario hispánico dan buena cuenta de la consolidación del microrrelato: de su éxito editorial, de la sintonía del género con el lector contemporáneo y de la amplitud de escritores que, casi de forma exclusiva, centran su actividad literaria en el microrrelato.

Con la entrada en el nuevo milenio, varias fueron las publicaciones que de manera monográfica reunieron, a partir de criterios diferentes, narrativas que se caracterizan por su hiperbrevedad, si bien es de justicia referirse a la antología de Fernández Ferrer (1990), La mano de la hormiga, por su carácter pionero. Como reza el subtítulo Los cuentos más breves del mundo y de las letras hispánicas recoge, siguiendo un orden alfabético, diversas composiciones hiperbreves, reuniendo a escritores tan dispares como Valéry, Merimée o Nietzsche, y a una significativa lista de autores hispánicos de diferentes generaciones como Monterroso, Borges, Bioy Casares, Mateo Díez o Merino. Esta amplitud diacrónica deja ver la intención implícita de que la colección funcione como una antología del cuento breve en el mundo hispano, tal como refiere el título. La aparición de Mateo Díez o Merino en esta antología, que hasta el momento no se habían significado por el cultivo de la minificción, funcionará como estímulo creativo para ambos, ya que a partir de ese momento, no solo publicarán microrrelatos, sino que serán utilizados a menudo como referentes de legitimación y canonización de la narrativa breve en el momento actual.

Por ejemplo, en el caso de Merino, en la resistente antología de Neuman (2010a). Esta es, no obstante, una publicación que se centra fundamentalmente en el cuento, tal como refleja el subtítulo, aunque varios de los textos seleccionados responden a la tipología microrrelatística. Véanse los de Felipe Benítez Reyes, Fernando Iwasaki, Hipólito Navarro o el propio Neuman. Todos ellos responden al arco generacional que se pretende representar en la antología, que recoge las creaciones de narradores españoles nacidos después de 1960 y que publican entre 1990 y 2001.

Esta apuesta por agrupar la producción de la última década y centrarse únicamente en escritores jóvenes perpetúa el carácter reivindicativo del manifiesto. Tal vez por ello -en ese juego de rebeldía y centralidad que disputa el microrrelato- el libro va prologado por José María Merino, que suma la autoridad del escritor consagrado al principio legitimador que persigue la colectánea. In-

12 Vid. Valls (2008: 303). 
siste el académico en que si no firma el resistente discurso inicial es únicamente por respeto generacional, apadrinando, de facto, la nueva oleada de escritores de cuentos.

Neuman (2010b) vuelve una década después con una nueva antología, con sus Pequeñas resistencias 5. Antología del nuevo cuento español (2001-2010). Los cuatro tomos anteriores se habían centrado, respectivamente, en el cuento contemporáneo centroamericano, sudamericano, caribeño y norteamericano. Al igual que en la iniciativa de 2001, continúa con el prefacio de un escritor consagrado (Eloy Tizón), el lapso temporal de diez años y la fecha de 1960 como límite de nacimiento de los escritores antologados. A diferencia del tomo anterior, prescinde de la poética de cada uno de los autores que precedía la selección de textos y opta por una encuesta final, con preguntas relacionadas con el cuento: acto de escritura, evolución del género o cuentistas preferidos.

Si el libro de 2002 se caracterizaba, como se ha dicho, por su espíritu reivindicativo, este asume el triunfo del género y las transformaciones del panorama editorial, mucho más permeable a este tipo de creaciones. Pese a ello, no renuncia a cierto espíritu resistente y afirma que prescinde de los autores ocasionales de cuento, desmarcándose de la oportunidad editorial y esporádica del relato breve.

Y, en este sentido, llama poderosamente la atención, por la importancia debida para el tema que nos ocupa, la exclusión en esta selección los microrrelatos "debido a la multiplicación de esta disciplina narrativa y a su crecimiento teórico, parece tener más sentido antologarla de manera diferente" (Neuman 2010b: 23.)

De modo que Neuman se apunta a la tesis de la diferencia genérica $y$, como veremos enseguida, parece que el desarrollo de la primera década del XXI resulta clave para la delimitación del microrrelato como modalidad literaria. A diferencia del libro de 2002, Neuman lo denomina como tal y lo diferencia del cuento.

José Luis González (2007) publica la primera edición de su antología en 1998, adelantándose a la abundante publicación de colecciones de microrrelato de la década siguiente. Abre la publicación un prólogo de Enrique Anderson Imbert, y en su introducción el editor advierte que en la selección incluye inéditos que obedecen a encargos personales.

Tanto el prologuista como el editor afirman la novedad de la brevedad, epítome de los tiempos posmodernos y, a tenor de lo advertido en la introducción, hay una finalidad pedagógica en esta antología, lo cual explica que los textos vayan precedidos de un comentario del editor.

Clara Obligado (2001 y 2009) publica también en dos ocasiones antologías exclusivas de microrrelato; en ambas opta en la cubierta por una cola de dinosaurio, con claras alusiones al conocido texto de Monterroso y, por consiguiente, con una evidente pretensión de situarlo en la tradición de la narrativa hiperbreve.

En relación a la concepción del género, el lapso de ocho años que va de la primera a la segunda manifiesta una mayor conciencia genérica, a través de la concreción terminológica y definición del microrrelato, similar a la advertida en las antologías de Neuman. Al igual que en la publicación de Neuman, en los aspectos paratextuales y organizativos de ambas obras, se percibe en la segunda 
una mayor definición del microrrelato en este decenio y su consiguiente consolidación. Si en la primera se refiere a los textos seleccionados como "relatos hiperbreves", en la segunda ya opta por "microrrelatos". Además, en esta segunda incluye un estudio introductorio de Francisca Noguerol, que pretende recoger parte de la producción teórica, consistente ya a estas alturas.

En la primera publicación (Obligado 2001) no establece criterios de selección de los textos, únicamente advierte que están organizados de forma menguante -a sugerencia de Hipólito Navarro- de modo que los microrrelatos van perdiendo extensión a medida que nos acercamos al final del libro, sugiriendo la cadencia descendente de la cola del dinosaurio. Tampoco aparecen numeradas las páginas de los microrrelatos, lo cual parece obedecer a un juego con el lector, una vez que el prólogo, la bibliografía o el índice, sí lo están.

En el segundo libro (Obligado 2009) apunta ya al término hegemónico "microrrelato" y explica la historia del primer libro, advirtiendo que por entonces pocos conocían el género. Este comentario refuerza la idea de la primera década del XXI como el periodo en que el microrrelato se consolida en España como forma literaria. Tal como afirma, el dinosaurio ya está en el Parnaso. Pese a ello, con la lógica periférica inherente al género, señala que prioriza en su selección a escritores casi ignotos.

En relación al prefacio de Francisca Noguerol, apunta las características de la minificción, apoyándose en los textos de la antología y enumera las siguientes: fantasía, terror, imagen, poesía, juegos metaficcionales y lingüísticos, y compromiso.

Precisamente el juego metaliterario inspira otra de las antologías publicadas. La editorial Tusquets edita la Galería de Hiperbreves, a cargo del Círculo Cultural Faroni (2001). La subversión y la parodia inspiran la existencia de dicho Círculo que, tal como apunta la nota preliminar, toma su nombre del personaje de Luis Landero, en Juegos de la edad tardía (1989). De ahí que a Landero le otorguen el honorífico cargo de Ujier Presidente y que el prólogo sea de Ignacio Vázquez Moliní, Jefe de Protocolo del Círculo. De hecho, también el concurso del que proceden gran parte de los textos ofrecía un premio singular: "los premios astronómicamente millonarios se concedieron en la moneda de países en quiebra, como 5 dinares, 50 marcos de Weimar o 10 zaires, llegamos a premiar con 50.000 pesetas en libros y, en la última edición, el galardonado se llevó 15 botellas de anís". (Círculo Cultural Faroni 2001: 139).

En lo que se refiere a la antología, recoge una selección de los relatos del Premio Internacional de Relato Hiperbreve, en sus cinco convocatorias (19962000), y es el único que establece un límite de extensión: quince líneas, siguiendo las normas del concurso.

La antología de Rotger y Valls (2005) también obedece a una iniciativa previa, en este caso la sección dedicada a microrrelatos de la revista Quimera. Los textos elegidos responden a encargos realizados por los editores y a una selección de los enviados a la revista. El prólogo tiene como objetivo delimitar el género y adelanta los argumentos que Valls desarrollará más tarde, y a los que ya hemos aludido. Afirman que es un género independiente que debe ser demarcado de las 
formas híbridas, próximas a él: "un microrrelato no es solo un alarde de ingenio y mucho menos un chiste. Como tampoco hay que confundirlo con el aforismo, la sentencia, la greguería, el bestiario, la fábula u otras formas breves en prosa que poseen su propia especificidad genérica codificada" (Rotger y Valls 2005: 12). Defienden la designación de microrrelato, por ser la más adecuada, en relación a los dos aspectos que marcan el género: la brevedad y la narratividad.

Del mismo año es la antología de Lagmanovich (2005), cuyo estudio introductorio ya se ha citado. Prescindimos por tanto de las consideraciones preliminares acerca del microrrelato, por habernos detenido ya en ellas. En cuanto a la selección, presenta una interesante novedad a nivel organizativo. El editor clasifica los textos diacrónicamente, insinuando "una posible organización para la historia -todavía no escrita- de la minificción hispánica moderna" (Lagmanovich 2005: 33).

En este sentido, conviene precisar que todas las antologías mencionadas se centran en el cuento o microrrelato en español, sin tener en cuenta la nacionalidad; es decir, integran escritores españoles o hispanoamericanos, a excepción de la antología de Neuman que, por la propia organización de la colección (volúmenes clasificados geográficamente), se centra únicamente en escritores españoles o hispanoamericanos que residan en España o hayan publicado al menos un libro en España.

Recientemente se han publicado tres nuevas antologías: Encinar y Valcárcel (2001), Andres-Suárez (2012) y Valls (2012). La primera de ellas, rompiendo la tónica predominante, parece preocuparse más por el microrrelato como producto cultural que por codificar genéricamente esta modalidad literaria:

\begin{abstract}
¿Por qué siempre que se habla de microrrelato, al igual que sucede con el cuento en general, hay que dedicar párrafos y páginas a la elección, preferencia y justificación de una denominación concreta? ¿Somos demasiado iconoclastas si afirmamos, ya desde el principio, que nos parece bien la mayoría de los múltiples términos, en muchos casos insólitas y originales creaciones léxicas, con los que se designa esta modalidad genérica de extraordinaria concisión narrativa: minificción, minicuento, microrrelato, microficción, ficción súbita, nanoficción, cuento muy breve, brevísimo o hiperbreve, relato ultracorto -mínimo, miniaturesco, cuántico, liliputiense, ascético, pigmeo, gnómico-, textículo, descuento o cuentín, entre otros? (Encinar y Valcárcel 2011: 11)
\end{abstract}

Con todo, optan en el título y a lo largo del prólogo por la designación microrrelato, consolidada ya a estas alturas, como hemos visto. Incluyen en las páginas preliminares una sucinta pero completa síntesis bibliográfica del microrrelato, tanto en España como en Hispanoamérica. No en vano, es el contexto hispano en general el que inspira la selección, aunando a escritores de ambos continentes. El criterio de inclusión es, por un lado, que hayan publicado un volumen de microrrelatos, en el espectro temporal de 1970 a 2010, arco de fechas que acota los textos recogidos.

Andres-Suárez (2011), por su parte, abandona las editoriales específicas (Menoscuarto, Páginas de Espuma) y opta por un sello especializado en clásicos 
literarios, Cátedra. Ello revela la voluntad de fijar canónicamente el microrrelato en la tradición literaria española, tal como recoge el subtítulo de la obra El cuarto género literario. Contribuyen a esta pretensión los propósitos enunciados en los criterios de selección de la antología (Andres-Suárez 2012: 92). Afirma la editora su originalidad respecto a otras en la primicia de ser la única que ofrece una historia completa del microrrelato en España (de 1906 a 2011) y que este recorrido histórico se realiza siguiendo la fecha de publicación de los textos, poniendo el foco en el género y no en los autores, y evidenciando la incorporación al microrrelato de cada uno de los autores incluidos. Por lo demás, el criterio de selección de los textos y autores obedece a la asiduidad de estos en cultivar el género, la condición de que los textos hayan sido publicados antes en un libro y la calidad literaria de los mismos.

En lo que se refiere al estudio introductorio que acompaña la selección, sintetiza los aspectos desarrollados en otros estudios y describe (a semejanza de lo hecho por Lagmanovich, 2010) el recorrido diacrónico seguido por el microrrelato, con una clara vocación de intervenir en el discurso historiográfico y fijarlo como un género canónico del mismo.

En cuanto a la antología de Valls (2012), no "pretende ser una antología canónica al uso, sino que su objetivo estriba en proporcionarle al lector un amplio panorama, espero que bastante plausible, acerca de los microrrelatos que se están escribiendo en castellano hoy en nuestro país" (Valls 2012: 21). En coherencia con lo enunciado, renuncia al repaso diacrónico de otras obras y se centra en escritores nacidos a partir de 1960, recogiendo textos de aquellos que cultivan el microrrelato con asiduidad, como de aquellos que lo han hecho ocasionalmente o por encargo. Resulta curiosa y original la recomendación del editor, respecto a la forma en que se debe leer el libro "del mismo modo en que leemos una antología de poemas de distintos autores, es decir, en pequeñas dosis, saboreando los textos y dejando reposar su lectura tras unas cuantas piezas" (Valls 2012: 21).

Por último, además de las antologías reseñadas podemos añadir también otras antologías de relatos breves, pero no exclusivas de escritores hispanos. Por ejemplo, la de Díez (2008), cuya primera edición data de 2002, que se centra en los cuentos y las "historias mínimas". No hay un deslinde genérico, en relación al cuento, y tampoco se puede decir que estas historias se correspondan todas ellas con microrrelatos, ya que a menudo suele integrar la formas híbridas próximas al relato, pero sin serlo, como ya se ha señalado en el episodio de integración del fragmento de La colmena como relato breve.

Es preciso referir, por su curiosidad, la iniciativa de la editorial Ediciones Irreverentes, que lanza una colección Cercanías, con obras que posibilitan su lectura en el metro o el transporte de cercanías. Así, uno de los títulos publicados, Microantología del Microrrelato (Rus 2009), vincula el género con los hábitos de lectura contemporáneos, tal como se ha advertido a lo largo de este artículo. No resulta sorprendente, por lo tanto, que la autora del prólogo, Alicia Arés (Rus 2009: 5), manifieste que el microrrelato es el género del siglo XXI que mejor representa esta sociedad vertiginosa. 


\section{Pentálogo conclusivo}

A modo de conclusión podemos establecer cinco aspectos, en relación con la génesis y consolidación del microrrelato en España:

-El microrrelato, en sus vertientes de brevedad y narratividad, explica su existencia y su desarrollo en el sistema literario español por la evolución de la narrativa durante el pasado siglo (estéticas de la posmodernidad).

- Las transformaciones socio-culturales que posibilitan la consolidación del microrrelato durante la presente década guardan grandes similitudes (expansión editorial, alteraciones estéticas y hábitos de lectura) con las habidas en la primera década del xx en relación al cuento.

-El microrrelato es un género de la resistencia: busca la centralidad, pero no renuncia a la subversión. Como tal, conserva su carácter contracultural, paródico, lúdico, pero la ingente crítica del XXI y las antologías intentan definir y delimitar el microrrelato y, en consecuencia, situarlo en la centralidad del campo cultural.

- La producción creativa y crítica de y sobre microrrelatos evidencia que su consolidación cultural como ¿género? (terminología, escritores consagrados, historia) se materializa a lo largo de la primera década del siglo xxı, pero no antes; por ello resulta aventurado aplicar está lógica delimitativa a textos de épocas pretéritas.

-Esta circunstancia permite concluir que, si bien no resulta unánime que la definición intrínseca de las formas hiperbreves se desmarque genéricamente del cuento, el campo literario español, a lo largo del periodo señalado en el punto anterior, delimita como producto cultural diferenciado el microrrelato.

\section{OBRAS CITADAS}

Álamo Felices, Francisco (2010): "El microrrelato. Análisis, conformación y función de sus categorías narrativas". En: Roas, David (ed.): Poéticas del microrrelato. Madrid, Arco Libros pp. 209-229.

Alanís, Armando (2011): "Decálogo de la minificción". En: El cuento en red, n. 24, p. 113.

Andres-Suárez, Irene y Rivas, Antonio (eds.) (2008): La era de la brevedad. El microrrelato hispánico. Palencia, Menoscuarto.

Andres-Suárez, Irene (2010): El microrrelato español. Una estética de la elipsis. Palencia, Menoscuarto.

_ (ed.) (2012): Antología del microrrelato español (1906-2011). El cuarto género narrativo. Madrid, Cátedra.

Cela, Camilo José (1989): La colmena. Madrid, Castalia.

Círculo Cultural Faroni (2001): Galería de hiperbreves. Barcelora, Tusquets.

Díez, Miguel (ed.) (2008): Antología de cuentos e historias mínimas (Siglos xIx y xx). Madrid, Austral [2002].

Encinar, Ángeles y Valcárcel, Carmen (eds.) (2011): Más por menos. Antología de microrrelatos hispánicos actuales. Madrid, Sial.

Ezama Gil, Ángeles (1998): "Las tendencias de la narrativa en la última década del siglo". En: García de la Concha, Víctor (dir.): Historia de la literatura española. 9. Siglo xIX (II). Madrid, Espasa-Calpe, pp. 795-800. 
(1992): El cuento en la prensa y otros cuentos. Aproximación al estudio del relato breve entre 1890 y 1900. Zaragoza, Universidad de Zaragoza.

Fernández Ferrer, Antonio (ed.) (1990): La mano de la hormiga. Los cuentos más breves del mundo y de las literaturas hispánicas. Alcalá de Henares, Fugaz Ediciones.

García Avilés, José Alberto (ed.) (2008): Dos minutos: microrrelatos. Madrid, Ediciones Internacionales Universitarias.

Gómez Trueba, Teresa (ed.) (2007): Mundos mínimos. El microrrelato en la literatura española contemporánea. Gijón, Cátedra Miguel Delibes-Libros del Pexe.

González, José Luis (ed.) (2007): Dos veces cuento. Antología de microrrelatos. Madrid, Ediciones Internacionales Universitarias [1998].

González Ariza, Fernando (2012): "Miles de pequeñas explosiones. El mercado del microrrelato en el mundo hispánico". En: Calvo Revilla, Ana y Navascués, Javier de (eds.): Las fronteras del microrrelato. Teoría y crítica de microrrelato español e hispanoamericano. Madrid/Frankfurt, Iberoamericana/Vervuert, pp. 91-97.

Grass, Roland y Risley, William (1979): Waiting for Pegasus. Studies of the Presence of Symbolism and Decadence in Hispanic Letters. Macomb, Wester Illinois University.

Lagmanovich, David (ed.) (2005): La otra mirada. Antología del microrrelato hispánico. Palencia, Menoscuarto.

(2008): "Minificción: corpus y canon". En: Andres-Suárez, Irene y Rivas, Antonio (eds.): La era de la brevedad. El microrrelato hispánico. Palencia, Menoscuarto, pp. 25-46.

Mainer, José Carlos (1987): La Edad de Plata (1902-1939). Ensayo de interpretación de un proceso cultural. Madrid, Cátedra.

Merino, José María (ed.) (1998): Cien años de cuentos (1898-1998). Antología del cuento español en castellano. Madrid, Santillana.

(2007): La glorieta de los fugitivos. Minificción completa. Madrid, Páginas de Espuma.

(2010): "De relatos mínimos". En: Roas, David (ed.): Poéticas del microrrelato. Madrid, Arco Libros, pp. 231-237.

Neuman, Andrés (ed.) (2010a): Pequeñas resistencias. Antología del nuevo cuento español. Madrid, Páginas de Espuma [2002].

(ed.) (2010b): Pequeñas resistencias. Antología del nuevo cuento español. Madrid, Páginas de Espuma.

(2011): "10 Microapuntes sobre el Microcuento". En: El cuento en red, n. ${ }^{\circ} 24$, p. 113.

Noguerol, Francisca (2010): "Micro-relato y posmodernidad: textos nuevos para un final del milenio". En: Roas, David (ed.): Poéticas del microrrelato. Madrid, Arco Libros, pp. 77-100.

Núñez Sabarís, Xaquín (2009): "Caminos inciertos, caminhos cruzados. La novela urbana en Camilo José Cela y Érico Veríssimo". En: Actas del VI Congresso Nacional da Associação Portuguesa de Literatura Comparada / X Colóquio de Outono Comemorativo das Vanguardas. Braga, Centro de Estudos Humanísticos-Universidade do Minho. Disponible en <http://ceh.ilch.uminho.pt>.

Obligado, Clara (ed.) (2001): Por favor, sea breve. Antología de microrrelatos. Madrid, Páginas de Espuma.

(ed.) (2009): Por favor, sea breve 2. Antología de microrrelatos. Madrid, Páginas de Espuma. 
Phillips, Allen W. (1974): "El arte y el artista en algunas novelas modernistas". En: Temas del modernismo hispánico y otros estudios. Madrid, Gredos, pp. 261-293.

Roas, David (2008): "El microrrelato y la teoría de los géneros". En: Andres-Suárez, Irene y Rivas, Antonio (ed.): La era de la brevedad. El microrrelato hispánico. Palencia, Menoscuarto, pp. 47-76.

(ed.) (2010): Poéticas del microrrelato. Madrid, Arco Libros.

(2010): "Sobre la esquiva naturaleza del microrrelato". En: Roas, David (ed.): Poéticas del microrrelato. Madrid, Arco Libros, pp. 9-42.

(2012): "Pragmática del microrrelato: el lector ante la hiperbrevedad". En: Calvo Revilla, Ana y Navascués, Javier de (eds.): Las fronteras del microrrelato. Teoría y crítica de microrrelato español e hispanoamericano. Madrid/Frankfurt, Iberoamericana/ Vervuert, pp. 53-63.

Ródenas de Moya, Domingo (2008): "El microrrelato en la estética de la brevedad del Arte Nuevo". En: Andres-Suárez, Irene y Rivas, Antonio (ed.): La era de la brevedad. El microrrelato hispánico. Palencia, Menoscuarto, pp. 25-46.

(2010): "Consideraciones sobre la estética de lo mínimo". En: Roas, David (ed.): Poéticas del microrrelato. Madrid, Arco Libros, pp. 181-207.

Rodríguez, Adriana Azucena (2011): "Cuentos mínimos a grandes rasgos (nanodecálogo)". En: El cuento en red, n. ${ }^{\circ} 23$, p. 24.

Rotger, Neus y Valls, Fernando (eds.) (2005): Ciempiés. Los microrrelatos de Quimera. BarceIona, Ediciones de Intervención Cultural.

Rus, Miguel Ángel de (ed.) (2009): Microantología del Microrrelato. Madrid, Ediciones Irreverentes.

Valle-Inclán, Ramón María de (1908): Corte de amor. Madrid, Imprenta de Balgañón y Moreno.

Valles Calatrava, José R. (2008): Teoría de la narrativa. Una perspectiva sistemática. Madrid/ Frankfurt, Iberoamericana/Vervuert.

Valls, Fernando (2008): Soplando vidrio y otros estudios sobre el microrrelato español. Madrid, Páginas de Espuma.

(ed.) (2012): Mar de pirañas. Nuevas voces del microrrelato español. Palencia, Menoscuarto.

Veríssimo, Érico (2005): Caminhos cruzados. São Paulo, Companhia das Letras.

Villanueva, Darío (1977): Estructura y tiempo reducido en la novela. Valencia, Bello. 